\title{
Anti- Aspergillus Fumigatus IgY Antibodies And Their Protective Efficacy In Cyclosporine A Treated-BALB/C Mice
}

\author{
Kohar Annie B. Kissoyan ${ }^{1}$, Nayla S. Al-Akl ${ }^{1}$, Fawwak Sleiman ${ }^{2}$, Alexander M. \\ Abdelnoor ${ }^{1 *}$ \\ ${ }^{1}$ Department of Experimental Pathology, Immunology and Microbiology, Faculty of Medicine and ${ }^{2}$ Department \\ of Animal Sciences, Faculty of Agriculture and Food Sciences, American University of Beirut, Beirut, Lebanon
}

\begin{abstract}
Previously, the protective efficacy of anti-Aspergillus fumigatus IgY antibodies; prepared in egg laying hens, was reported in immunocompetent BALB/c mice. Since A. fumigatus infections are of main concern in immunocompromised patients, the aim of this study was to test the efficacy of the same product in Cyclosporine A treated-BALB/c mice.

Heat- killed A. fumigatus was emulsified with both Freund's complete and incomplete adjuvant and injected into egg-laying hens with a 12 days interval between the former and the latter emulsions. IgY was extracted from pooled egg yolks laid prior to, post- primary and post- secondary immunizations, and were dialyzed and lyophilized. Elevated levels of protein and IgY in the post-immunized preparations was confirmed by the Bradford assay and polyacrylamide gel electrophoresis (PAGE).Earlier specific IgY was detected by Enzyme Linked Immunosorbent Assay (ELISA). The different extracts obtained were administered to mice treated with Cyclosporine A and challenged with an LD50 of A. fumigatus and survival rates were determined.Results indicated that $\operatorname{Ig} Y$ concentrations were highest in postsecondary immunized extracts and was most effective in protecting Cyclosporine A treatedmice against challenge with A. fumigatus.It appears that IgY antibodies provided some therapeutic and prophylactic effects in Cyclosporine A treated-mice. Probably better protective and therapeutic results would be obtained by manipulating the dose of post-IgY.
\end{abstract}

KEYWORDS : Fungus, Immunocompromised, vaccination

\section{INTRODUCTION}

Aspergillus is a large genus containing more than 180 species, among which the most common etiological agent of human disease is Aspergillus fumigatus [1]. A. fumigatus is a ubiquitous, cosmopolitan, and saprophytic fungus [2,3]. The primary ecological niche of A. fumigatus is the soil or decaying vegetation, however, the small and hydrophobic conidia produced by the fungus disperse easily into the air, making exposure a universal phenomenon [3,4]. The effect of the fungus is largely dependent on the immune status of the host; it does not usually cause disease in immunocompetent individuals. However, in immunocompromised individuals it can cause life threatening diseases. A. fumigatus can cause diseases such as allergic bronchopulmonary aspergillosis (ABPA), noninvasive aspergilloma, and invasive aspergillosis (IA); the latter being the most devastating disease, targeting mostly the severely immunocompromised patients [2]. Patients at greatest risk to develop IA include individuals with hematological malignancies, such as leukemia and other malignancies, solid- organ and hematopoietic stem cell transplant patients, patients with genetic immunodeficiencies such as chronic granulomatous disease, and individuals with advanced human immunodeficiency virus disease $[2,4,5]$. Mortality rates of IA range from $40 \%$ to $90 \%$ depending on the degree of immune suppression, site of infection and treatment regimen used [2]. Concerning IA treatment the limited number of active and non-toxic antifungal agents and the emergence of resistant strains calls for searching for other means either to prevent or treat Aspergillus mediated diseases [4, 6 and 7]. Among human pathogens, fungal diseases are the only type of diseases where vaccines for human use are not available [1]. However, a number of reports dealt with potential vaccines in animal models [8]. Furthermore, the immunocompromised population, are not eligible for active immunization, thus passive immunization would be a resort. 
Chicken egg yolk is thought to be an appropriate alternative for mammalian antibody production [9].Chicken housing is inexpensive, feeding is cheap, no invasive protocols are used and $\operatorname{IgY}$ ( IgG equivalent) isolation is time efficient, simple, and hygienic [10]. In earlier studies conducted at our laboratory, IgY anti- Candida albicans antibodies and IgY anti- A. fumigatus antibodies proved to be protective and therapeutic in immunocompetent BALB/c mice upon their challenge with lethal doses of Candida albicans and A. fumigatus respectively when given prior to, simultaneously with, or after the fungal challenge [11, 12] . However, since the immunocompromised population is the main target of the life threatening diseases caused by Aspergillus, the aim of the present study was to see if anti-A. fumigatus IgY antibodies had a similar effect in Cyclosporine A treated-mice. Egg laying hens were immunized with A. fumigatus, IgY was extracted from the yolk of laid eggs, and the protective and therapeutic effect of the specific IgY antibodies was tested in Cyclosporine A treated mice.

\section{MATERIALS AND METHODS}

\subsection{Preparation of IgY Anti A. fumigatus Antibodies in Egg Laying Hens:}

\subsection{Immunization of egg laying hens.}

An isolate of A. fumigatus was obtained from the diagnostic microbiology laboratory at the American University of Beirut Medical Center and cultured on Sabouraud dextrose agar at $25^{\circ} \mathrm{C}$ for 3 days.A suspension of A. fumigatus, prepared in PBS, having an absorbance of 1 at a wavelength of $480 \mathrm{~nm}$ was heated at $80^{\circ} \mathrm{C}$ for 1 hour. Equal volumes of this preparation and Freund's Complete Adjuvant (Af-FCA) or Freund's Incomplete Adjuvant ( $A f$-FIA) were emulsified. Two egg laying hens were injected subcutaneously with $2 \mathrm{ml}$ of $A f$-FCA (primary immunization) and 12 days later with $2 \mathrm{ml}$ of $A f$-FIA (secondary immunization).

\subsection{Egg collection and IgY extraction}

Eggs were collected 3 days prior to primary immunization (control), on days 8, 9, 10 and 11 postprimary immunization and on days 19 to day 33 post-secondary immunization. Each of the 3 egg collections yolk from the two hens were pooled. IgY was extracted from each of the three pooled egg yolk preparations using the EGGstract® IgY Purification System Protocol (Promega Corporation, WI, USA). The extracts were dialyzed against distilled water for a period of 4 days and lyophilized.

\subsection{Protein levels, Polyacrylamide Gel Electrophoresis (PAGE) and Specific IgY levels of Pre- Immunization, Post-Primary and Post-Secondary Immunization IgY Extracts.}

The protein concentrations of the 3 pooled extracts were determined by the Bradford assay® (Bio-Rad, Hercules, California, USA) [13]. PAGE was performed according to Life Science Products Protocol, ORTEC Incorporated, Oak Ridge, Tennessee, USA. Briefly, the running gel in the slab consisted of 4 layers having different gel concentrations. A first layer of $20.4 \mathrm{ml}$ of $8 \%$ gel was loaded, followed by a layer of $3.8 \mathrm{ml}$ of $6 \%$ gel, then a layer $2.2 \mathrm{ml}$ of $4.5 \%$ gel and a final layer of $4 \mathrm{ml}$ of $8 \%$ gel. After complete polymerization, the slab containing- gel was placed into the buffer tank and the samples were loaded. Twenty $\mu$ l of each of preimmunization (control), post- primary immunization and post-secondary immunization preparations $(50 \mathrm{mg} / \mathrm{ml})$ were mixed thoroughly with $20 \mu \mathrm{l}$ of $50 \%$ sucrose. Each sample was loaded to a well, followed by an $8 \%$ sealing cap gel. The current was allowed to run for 2 hours, at $40 \mathrm{~mA}$. Next, the gel was removed from the slab and placed in a $1 \%$ Naphthalene Black dye dissolved in $7 \%$ acetic acid for 1 hour. After complete staining, the gel was transferred into a $7 \%$ acetic acid de-staining solution until background was completely de-stained and bands were clear and visible. The gel was visualized using light transilluminator (ULTRA LUM, Dual Light Transilluminator, Claremont, CA). Band intensities were analyzed and compared using UVP Doc-It LS EC3 Imaging System (Ultra Violet Products Ltd., Cambridge, UK). Percentages of the band intensities were calculated and compared to the intensities of the control bands. Earlier, specific anti- A. fumigatus IgY antibodies were detected by ELISA (12),

\subsection{Evaluation of the Protective Efficacy of IgY - Anti A. fumigatus Antibodies in Cyclosporine A Treated-Mice}

Forty eight female BALB/c mice, 6-8 weeks old, were divided into eight groups, each group containing six mice. Cyclosporine A $(30 \mathrm{mg} / \mathrm{kg}$, the maximum dose that could be used without causing death) dissolved in olive oil was injected intraperitoneally (i.p.) daily to mice, for a period of 10 days. The protocol for the treatment of mice with post- primary and post secondary extracts in relation to Cyclosporine A administration and challenge with LD 50 of A. fumigatus is given in Table 1. Mice were monitored on a daily basis, and the number of deaths /day was recorded. Dead mice were dissected, gross morphological changes were observed, the lungs and kidneys were homogenized and the homogenates were cultured on Sabouraud Agar plates to confirm that the death was due to the A. fumigatus. 
Anti- Aspergillus Fumigatus Igy Antibodies...

\subsection{Statistical analysis}

Whenever applicable, data were expressed as Mean \pm SD. To test for significance of survival rates between groups, the Kaplan Meier curve was generated. Differences were considered significant at a P value $\leq 0.05$.

\section{RESULTS}

\subsection{Protein Concentration}

Protein concentrations of the pooled extracts from eggs laid by hens 1 and 2 are given in Table 2.

Protein levels were higher for both post-primary $(9.215 \mathrm{mg} / \mathrm{ml})$ and post-secondary immunization $(8.23 \mathrm{mg} / \mathrm{ml})$ extracts as compared to the pre-immunization control extracts $(6.73 \mathrm{mg} / \mathrm{ml})$.

\subsection{Quantification of IgY Bands Using PAGE}

The electrophoretic pattern of pre-, post-primary and post-secondary immunization IgY extracts is given in Fig. 1. The IgY band had a molecular weight of about 180,000 D. The highest band intensity was seen for the post-secondary immunization extract followed by the band obtained in the post-primary immunization extract. The intensity of the IgY band in the post- primary immunization sample was $41 \%$ more than that of the control sample. Whereas the intensity of the IgY band in the post-secondary immunization sample was $56 \%$ more than that of the control sample.

3.3, Anti-A. fumigatus Specific IgY levels. Earlier it was reported that in ELISA the absorbance obtained assaying post-immunized egg yolk extract was about 6 times that obtained when pre-immunized egg yolk extract was assayed

\subsection{Evaluation of the Protective Efficacy of IgY Anti- A. fumigatus Antibodies in Cyclosporine A Treated-Mice}

Survival of the immunocompromised mice, challenged with A. fumigatus, and treated with postimmunization egg yolk extracts, at different times with respect to the fungal challenge are represented in Table 3. Mice receiving only the diluents (olive oil and PBS) along with the fungus had a 50\% survival rate. All Cyclosporine A treated mice that received only PBS without any extracts died. No survival was observed in Cyclosporine A treated mice that received post-primary immunization $\operatorname{IgY}$ extracts, given prior to, simultaneously with, or after challenge with the fungus. On the other hand, prolonged survival and statistically significant higher survival rates were obtained in the groups that received post-secondary immunization extracts as compared to the control group treated only with Cyclosporine A and challenged with fungus (Tables 4). Four of 6 mice survived in the group that received the post- secondary immunization IgY extract 24 hours before the fungal challenge $(67 \%$ survival with a $\mathrm{p}$ value $=0.002$ when compared to control Cyclosporine A only treated group), 3 of 6 mice survived in the group that received the post-IgY extract simultaneously with the fungal challenge ( $50 \%$ survival with $\mathrm{p}$ value $=0.002$ when compared to control Cyclosporine A only treated group) and 2 out of 6 mice survived in the group that received post-secondary immunization IgY extract 24 hours after the fungal challenge ( $33 \%$ survival with $\mathrm{p}$ value $=0.005$ when compared to control Cyclosporine A only treated group). In addition, a delay in time of death was observed in all the groups receiving the post- secondary immunization extract compared to the rest of the groups. A Kaplan Meier curve was generated to elucidate the survival rate (Fig. 2). Lung and kidney obtained from dead mice were homogenized and cultured onto Sabouraud agar. Growth of A. fumigatus indicated that death was due to the fungal infection.

\section{DISCUSSION}

A. fumigatus does not usually cause disease in the immunocompetent host. However, in the immunocompromised host it can cause serious life-threatening infections. Although A. fumigatus is susceptible to a number of antifungal agents including voriconazole, caspofungin, micafungin, posaconazole and itraconazole, alone they are usually not capable of controlling the fungal infection; the host's immunocompetent system is needed as well. Moreover, there is always the fear that resistant strains might emerge. Hence the need for alternative means of prevention and treatment. One would consider the preparation of an active vaccine, but of what benefit would it be in an immunocompromised individual? An alternative would be to prepare a passive vaccine that could be used for prophylaxis and therapy.Conventional methods of preparing polyclonal antibodies include the immunization of a horse, rabbit or sometimes a goat, bleed the animal, separate the serum and purify the gamma globulin. In this study we aimed at finding an easier, faster, more ethical and economical method at developing such a vaccine. We selected to use egg laying-hens to produce IgY antibodies, the equivalent of human IgG. Ethically, being a non- invasive process, and economically, hens being relatively 
easier and cheaper to raise and feed [14, 15]. Furthermore, purification and extraction of $\operatorname{IgY}$ immunoglobulins is easily done from egg yolk and yields higher concentrations and pure form of $\operatorname{IgY}$ as compared to larger animals since a considerable amount of IgY produced by hens, ends up in the yolk sac. [10, 16]. In earlier studies anti-human lymphocyte antibodies, anti-Candida albicans and anti- A. fumigatus antibodies were prepared in egg- laying hens, in our laboratory. The presence of anti-human lymphocytes antibodies was detected in vitro. The presence of anti-Candida albicans and anti-A. fumigatus IgY antibodies was confirmed in vitro and were proved to be protective and therapeutic in immunocompetent BALB/c mice $[11,12,17]$. However, since A. fumigatus is a concern mostly in the immunocompromised population, testing for the efficacy of passive vaccination against A. fumigatus in mice treated with an immunosuppressive agent, Cyclosporine A, gives insight for possible effective therapy in immunocompromised patients. Determination of higher protein levels and the appearance of more intense $\operatorname{IgY}$ bands in PAGE in post-immunized IgY as compared to pre-immunized IgY was indicative of the presence of IgY-anti-A fumigatus antibodies in egg yolk extracts from post-immunized hens. Moreover, specific IgY was detected in post-immunization egg yolk extract (12). Treatment of immunocompromised mice with immunization extract provided protection against challenge with a lethal dose of $A$. fumigatus. It can be noted that only post- secondary extract, administered $24 \mathrm{hrs}$ before, $24 \mathrm{hrs}$ later or simultaneously with fungal challenge, offered significant prolonged survival of mice as compared to post-primary immunization extracts treated groups. Survival was best observed when post- secondary extract was administered $24 \mathrm{hrs}$ before or concomitantly with fungal challenge, indicating that timing might be an important criterion. The mechanism by which $\operatorname{IgY}$ is protective is yet to be determined. It has been suggested that $\mathrm{IgY}$ behaves as an opsonin [9]. It is worth mentioning that $\mathrm{IgY}$ is foreign to humans and some individuals suffer from allergic reactions to eggs. However, the use of an $\mathrm{IgY}$ passive vaccine in immunocompromised individuals who had a history of allergy to eggs should not be of concern.

\section{CONCLUSION}

It appeared that IgY antibodies provided some therapeutic and prophylactic effects in Cyclosporine A treated-mice. Probably better protective and therapeutic results would be obtained by manipulating the dose of post-immunized IgY. It can be suggested to consider testing the efficacy of immune IgY in animals that are phylogenetically close to humans and if proven to be effective, clinical trials can be considered.

\section{ACKNOWLEDGEMENTS}

An acknowledgement section may be presented after the conclusion, if desired.

Table 1: Treatment protocol for the assessment of the protective efficacy of IgY rich-yolk extracts on Cyclosporine A treated-mice.

\begin{tabular}{|c|c|c|c|c|c|c|c|c|}
\hline & Group 1 & Group 2 & Group 3 & Group 4 & Group 5 & Group 6 & Group 7 & Group 8 \\
\hline $\begin{array}{l}\text { Day 0- } \\
10\end{array}$ & & & & Cyc & sporine A $(30$ & ng/kg) & & \\
\hline $\begin{array}{l}\text { Injecte } \\
\text { d with }\end{array}$ & $\begin{array}{c}\text { A. } \\
\text { fumigatus } \\
+ \text { Olive } \\
\text { oil+ PBS }\end{array}$ & $\begin{array}{c}\text { A. } \\
\text { fumigatus } \\
+ \text { PBS }\end{array}$ & $\begin{array}{c}\text { PPI extract } \\
+ \text { A.fumigat } \\
\text { us (24hrs } \\
\text { later) }\end{array}$ & $\begin{array}{c}\text { A.fumigatus } \\
+ \text { PPI } \\
\text { extract (at } \\
\text { the same } \\
\text { time) }\end{array}$ & $\begin{array}{c}\text { A.fumigatu } \\
\text { s+ PPI } \\
\text { extract } \\
\text { (24hrs } \\
\text { later) }\end{array}$ & $\begin{array}{c}\text { PSI extract } \\
+ \text { A.fumigat } \\
\text { us (24hrs } \\
\text { later) }\end{array}$ & $\begin{array}{c}\text { A.fumigatu } \\
\text { s+ PSI } \\
\text { extract (at } \\
\text { the same } \\
\text { time) }\end{array}$ & $\begin{array}{c}\text { A.fumigatu } \\
\text { s+ PSI } \\
\text { extract } \\
\text { (24hrs } \\
\text { later) }\end{array}$ \\
\hline \multicolumn{9}{|c|}{$\begin{array}{l}\text { Six mice per group, Cyclosporine A dose }=30 \mathrm{mg} / \mathrm{kg} / \text { daily, challenge dose of } A \text {. fumigatus }=\text { LD50 }(39.45 \text { units }) \text {, PPI } \\
\text { extract }=\text { Post- primary IgY* extract }(2 \mathrm{mg} / \mathrm{mouse}), \text { PSI extract }=\text { Post-secondary IgY } * \text { extract }(2 \mathrm{mg} / \mathrm{mouse})\end{array}$} \\
\hline
\end{tabular}


Table 2: Protein concentration of egg yolk extracts.

\begin{tabular}{l|l}
\hline Egg Yolk Extracts dissolved in PBS & $\begin{array}{l}\text { Protein Concentration } \\
(\mathbf{m g} / \mathbf{m l})^{*}\end{array}$ \\
\hline $\begin{array}{l}\text { Control } \\
\text { Pre-immunization }\end{array}$ & $6.73 \pm 1.61$ \\
$\begin{array}{l}\text { Days 8-11 } \\
\text { Post-primary immunization }\end{array}$ & $9.215 \pm 2.28$ \\
\hline $\begin{array}{l}\text { Days 19-33 } \\
\text { post-secondary immunization }\end{array}$ & $8.23 \pm 1.47$ \\
\hline
\end{tabular}

*Averages obtained from Hen 1 and Hen 2 on specific days

Table 3: Numbers of deaths/day in the different groups of mice

\begin{tabular}{|c|c|c|c|c|c|c|c|c|}
\hline Day & Group1 & Group 2 & Group 3 & Group 4 & Group 5 & Group 6 & Group 7 & Group 8 \\
\hline $\begin{array}{l}\text { Number of } \\
\text { mice/group }\end{array}$ & 6 & 6 & 6 & 6 & 6 & 6 & 6 & 6 \\
\hline IgY extract(ml) & 0 & 0 & 0.2 & 0.2 & 0.2 & 0.2 & 0.2 & 0.2 \\
\hline Day 0 & 0 & 0 & 0 & 0 & 0 & 0 & 0 & 0 \\
\hline Day 1 & 0 & 0 & 0 & 0 & 0 & 0 & 0 & 0 \\
\hline Day 2 & 0 & 4 & 1 & 2 & 4 & 0 & 0 & 0 \\
\hline Day 3 & 2 & 2 & 4 & 4 & 2 & 1 & 1 & 2 \\
\hline Day 4 & 0 & 0 & 1 & 0 & 0 & 0 & 2 & 1 \\
\hline Day 5 & 1 & 0 & 0 & 0 & 0 & 1 & 0 & 1 \\
\hline Day 6 & 0 & 0 & 0 & 0 & 0 & 0 & 0 & 0 \\
\hline Day 7 & 0 & 0 & 0 & 0 & 0 & 0 & 0 & 0 \\
\hline $\begin{array}{l}\text { Total number of } \\
\text { dead mice }\end{array}$ & 3 & 6 & 6 & 6 & 6 & 2 & 3 & 4 \\
\hline Survival rate & $50 \%$ & $0 \%$ & $0 \%$ & $0 \%$ & $0 \%$ & $67 \%$ & $50 \%$ & $33 \%$ \\
\hline
\end{tabular}

*Groups are defined in Table 1

Table 4: Comparison of survival rates between all groups and the control Cyclosporine A treated group challenged with A. fumigatus,

\begin{tabular}{llc}
\hline \multicolumn{1}{c}{ Treatment } & $\begin{array}{l}\text { Group 2: Cyclosporine A + } \\
\text { A. Fumigatus + PBS }\end{array}$ \\
\cline { 2 - 3 } & Chi- Square & P value \\
\hline Group 1: A. fumigatus + Olive Oil & 7.787 & 0.005 \\
Group 3: PPI extract + A. fumigatus (24hrs later) & 3.190 & 0.074 \\
Group 4: A. fumigatus + PPI extract (at the same time) & 1.222 & 0.269 \\
Group 5: A. fumigatus + PPI extract (24hrs later) & 0.000 & 1.000 \\
Group 6: PSI extract + A. fumigatus (24hrs later) & 9.355 & 0.002 \\
\hline
\end{tabular}


Anti- Aspergillus Fumigatus Igy Antibodies...

\begin{tabular}{lcc}
\hline Group 7: A. fumigatus + PSI extract (at the same time) & 9.355 & 0.002 \\
Group 8: A. fumigatus + PSI extract (24hrs later) & 7.787 & 0.005 \\
\hline
\end{tabular}

PPI: Post-primary immunization extracts, PSI: Post-secondary immunization extracts

Significance is described as P-values

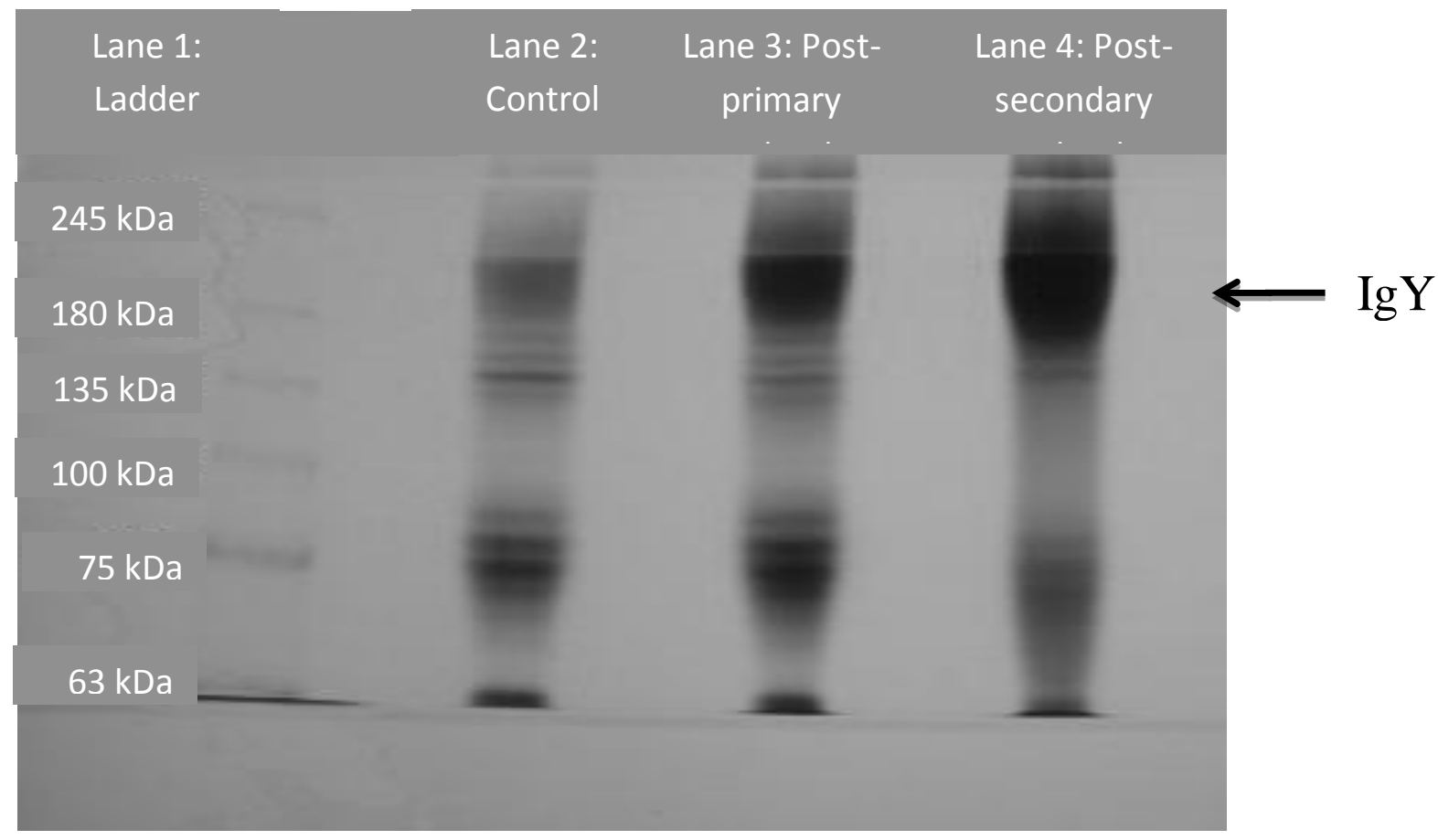

Figure 1: PAGE electrophoresis pattern of the pooled IgY preparations. Lane 1: Ladder (63-245 kDa), Lane 2:pre-immunization IgY extract, Lane 3: post- primary immunization IgY extract, Lane 4: post-secondary immunization IgY extract.

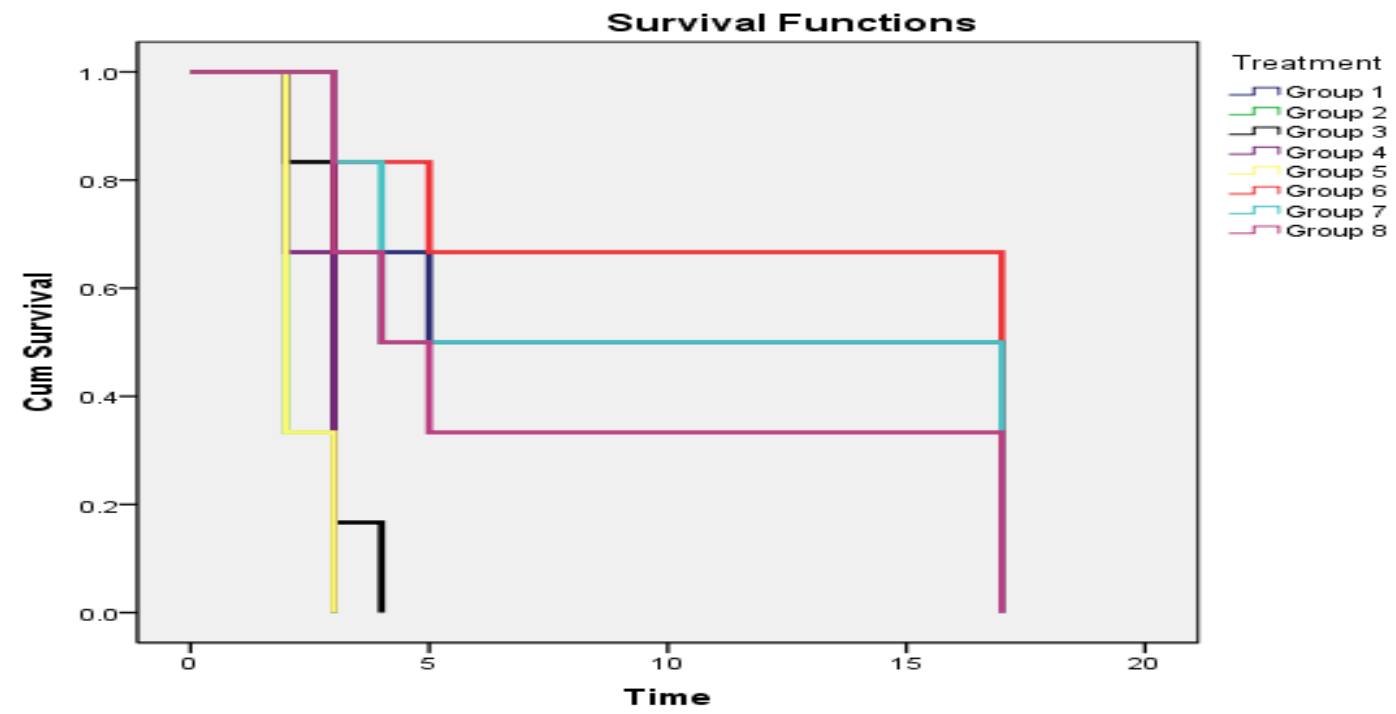

Figure 2: Kaplan-Meier survival curve. Mice survival rate was prolonged when treated with post-secondary immunizaion IgY extracts whether $24 \mathrm{hrs}$ before, later or simultaniously to A. fumigatus challenge ( Groups 6,7 and 8) . Post secondary IgY alone increased survival rate as compared to the control groups receiving either A. fumigatus alone (Group 1) or Cyclosporine A treatment along with fungal challenge (Group 2). Refer to Table 1 for group identification. 


\section{REFERENCES}

[1] A. Carvalho, C. Cunha, R. G. Iannitti, A. De Luca, G. Giovannini, F. Bistoni and L. Romani, Inflammation in aspergillosis: The good, the bad, and the therapeutic, Annals of the New York Academy of Sciences, 1273, 2012, 52-59.

[2] T. R. T. Dagenais and N. P. Keller, Pathogenesis of Aspergillus fumigatus in invasive aspergillosis, Clin. Microbiol. Rev., 22(3), 2009, 447-465.

[3] M. K. Mansour, J. M. Tam and J. M. Vyas, The cell biology of the innate immune response to Aspergillus fumigatus, Annals of the New York Academy of Sciences, 1273(1), 2012,78-84

[4] J. -. Latgé, Aspergillus fumigatus and Aspergillosis, Clin. Microbiol. Rev., 12(2), 1999, 310-350.

[5] V. P. Kurup and A. Kumar, Immunodiagnosis of aspergillosis, Clin. Microbiol. Rev., 4(4), 1991, $439-456$.

[6] J. E. Cutler, G. S. Deepe Jr. and B. S. Klein, Advances in combating fungal diseases: Vaccines on the threshold, Nature Revie ws Microbiology, 5(1), 2007, 13-28.

[7] R. Sherif and B.H. Segal, Pulmonary aspergillosis: Clinical presentation, diagnostic tests, management and complications, Curr. Opin. Pulm. Med, 16(3), 2010, 242-250.

[8] S. Bellocchio, S. Bozza, C. Montagnoli, K. Perruccio, R. Gaziano, L. Pitzurra and L. Romani, Immunity to Aspergillus fumigatus: The basis for immunotherapy and vaccination, Medical Mycology, 43(Suppl 1), 2005, S181-S188.

[9] E. Spillner, I. Braren, K. Greunke, H. Seismann, S. Blank and D. du Plessis, Avian IgY antibodies and their recombinant equivalents in research, diagnostics and therapy, Biologicals, 40(5), 2012, 313-322.

[10] J. Kovacs-Nolan and Y. Mine, Passive immunization through avian egg antibodies, Food Biotechnol., 18(1), 2004, 39-62.

[11] A.M. Abdelnoor, E. Rahal, J.A. Zeidan, Y.A. Halas and F. Sleiman, Preparation of Anti-Candida albicans Antibodies in an eggLaying Hen and their ProtectiveEfficacy in Mice, Journal of Applied Research, 6(1), 2006, 62-68.

[12] M. Chakhtoura, E. Rahal, Y. Halas, Z. Al-Sabbagh and A. M. Abdelnoor, Preparation of anti-Aspergillus fumigatus antibodies in egg laying hens and their protective efficacy in BALB/c mice, Journal of Applied Research, 8(2), 2008, 168-177.

[13] M. M. Bradford, A rapid and sensitive method for the quantitation of microgram quantities of protein utilizing the principle of protein dye binding, Anal. Biochem., 72, 1976, 248-254.

[14] R. Chalghoumi, Y. Beckers, D. Portetelle and A. Théwis, Hen egg yolk antibodies (IgY), production and use for passive immunization against bacterial enteric infections in chicken: A review, Biotechnology, Agronomy and Society and Environment, 13, 2009, 295-308.

[15] W. Dias da Silva and D. V. Tambourgi, IgY: A promising antibody for use in immunodiagnostic and in immunotherapy, Vet. Immunol. Immunopathol., 135 , 2010, 173-180.

[16] M. Tini, U. R. Jewell, G. Camenisch, D. Chilov and M. Gassmann, Generation and application of chicken egg-yolk antibodies, Comparative Biochemistry and Physiology - A Molecular and Integrative Physiology, 131(3), 2002, 569-574.

[17] L. Avedenian, R. Khauli, F. Sleiman, E. A. Rahal, and A. M. Abdelnoor, Preparation of Chicken Anti-Human Lymphocyte Globulin (IgY). Clinical and Investigative Medicine, 27(4), 2004, 132.

[18] P. J. Morris, Cyclosporin A, Transplantation, 32(5), 1981, 349-354

[19] S. V. Efimov, F. K. Karataeva, A. V. Aganov, S. Berger and V. V. Klochkov, Spatial structure of cyclosporin A and insight into its flexibility, J. Mol. Struct., 1036, 2013, 298-304. 